\title{
Breast reconstruction in the high-risk population: current review of the literature and practice guidelines
}

\author{
Margaret S. Roubaud ${ }^{1}$, Joseph N. Carey ${ }^{2}$, Emma Vartanian $^{2}$, Ketan M. Patel $^{2}$ \\ ${ }^{1}$ Department of Plastic and Reconstructive Surgery, University of Texas, MD Anderson Cancer Center, Houston, TX, USA; ${ }^{2}$ Department of Plastic \\ and Reconstructive Surgery, University of Southern California, Los Angeles, CA, USA \\ Contributions: (I) Conception and design: MS Roubaud, JN Carey, KM Patel; (II) Administrative support: MS Roubaud, E Vartanian; (III) Provision \\ of study materials or patients: MS Roubaud; (IV) Collection and assembly of data: MS Roubaud; (V) Data analysis and interpretation: All authors; (VI) \\ Manuscript writing: All authors; (VII) Final approval of manuscript: All authors. \\ Correspondence to: Margaret S. Roubaud, MD. 1400 Pressler St., Unit 1488, Houston, TX 77030, USA. Email: MSRoubaud@mdanderson.org.
}

\begin{abstract}
Breast reconstruction is an important part of the cancer treatment paradigm and the psychosocial benefits are well described in the literature. Notably, breast reconstruction restores both the functional and emotional losses patients experience due to tumor resection. Post-cancer quality of life is an important benchmark of successful treatment; therefore, breast reconstruction is an essential component that should be offered whenever possible. Over time, reconstructive techniques and outcomes have improved dramatically resulting in better patient safety and decreased operative morbidity. When counseling a patient for surgery, the provider must consider all aspects of a patient's health. Ideally, breast cancer patients should be physically, emotionally, and oncologically appropriate candidates for reconstruction. However, in concerted effort to provide opportunities for as many patients as possible, the definition of who is a good candidate for reconstruction has evolved to include higher risk patients. These patients include those with advanced age, nicotine use, obesity, and significant ptosis. With improvements in surgical procedures and perioperative care, this population may also benefit from restorative surgery. However, the exact risk of complications and necessary counseling has gone largely undefined in this population. This article examines particular "highrisk" groups that may be challenging for extirpative and reconstructive surgeons and offers current guidelines for practice.
\end{abstract}

Keywords: High-risk; breast; reconstruction; obese; ptotic; elderly; smoking

Submitted Feb 19, 2020. Accepted for publication Jun 03, 2020.

doi: $10.21037 / \mathrm{gs}-2020$-nfbr-09

View this article at: http://dx.doi.org/10.21037/gs-2020-nfbr-09

\section{Introduction}

Since the passage of the Women's Healthcare and Cancer Right's Act of 1998, breast reconstruction has fortunately increased in both frequency and number of options offered. Accordingly, important outreach initiatives have followed including an internationally-recognized annual Breast Reconstruction Awareness Day and other educational endeavors that improve patient's knowledge and access to care. Simultaneously, within the medical community, multidisciplinary care of the breast cancer patient has grown to routinely include medical, radiation, and surgical oncology as well as plastic and reconstructive surgery.

While breast reconstruction remains a pillar of breast cancer treatment, not all patients may be appropriate candidates, based on medical, physiological, anatomic and oncologic conditions. Patients with high risk conditions may desire breast reconstruction, but may be counseled that the reason that they are "high risk" is that their medical conditions result in an increased likelihood of complications. Complications after breast reconstruction have been shown to affect patient emotional well-being, health-related quality of life, and satisfaction and should be considered prior to offering care (1-4). In this review, 
such potential high-risk groups are defined and the current literature examined for the most up-to-date reconstructive recommendations.

\section{Defining a high-risk population}

Patients who are considered at increased risk for reconstructive surgical complications include those who present with medical diagnoses, or physical conditions that predispose them to infection, mastectomy flap necrosis, perioperative morbidity, or reconstructive failure. The consequences of these complications include pain, longterm disability, scarring, but of most importance, possible delay in adjuvant treatments that could affect oncologic outcome, or even survival. While a single high-risk factor alone may not preclude a breast reconstruction, patients with multiple risk factors should be judiciously evaluated and advised. The importance of defining high risk groups is to ultimately assess the risk of complications, and their potential effects on breast reconstruction patients.

\section{High-risk groups}

\section{Elderly}

Nearly $75 \%$ of breast cancer is diagnosed in patients over 65 years. With the rapidly increasing elderly population, breast cancer treatment providers must consider this select group. In the past, some surgeons did not offer reconstruction in elderly patients, with one study finding the biggest single predictor for offering reconstruction being a patient age under 50 years (5). With increasing breast cancer survival rates, this tendency may leave patients without reconstruction for decades. While age is always a consideration regarding the overall health and tolerance of a surgical candidate, increasing data across multiple disciplines have demonstrated that the global health of the patient is more predictive of successful outcomes than chronology alone.

In a recent review from the United Kingdom, the authors found that breast reconstructive surgery is well tolerated in the elderly population, with complication rates comparable to a younger group (6). Importantly, in areas such as social functioning and emotional well-being, patients with reconstructive surgery displayed better outcomes than those without. This data is reinforced by multiple other studies with similar findings, demonstrating both comparable safety and patient satisfaction in the elderly reconstructive population (7-10).

Interestingly, many studies have also demonstrated that in the elderly population, autogenous reconstruction produced better results than implants $(6,11,12)$. While there may be a bias to use implants in older women to reduce anesthetic time, decreasing long-term satisfaction, increasing complication rates, and increasing number of revision procedures may outweigh this perceived benefit (12-14). Furthermore, recent evidence suggests that age greater than 65 may be an independent risk factor for perioperative complications following expander/implantbased reconstruction (15). When evaluating the safety of autologous reconstruction in the elderly, a study in women older than 65 years versus women younger than 65 years found there was no significant difference in overall complication rates (16). Furthermore, on patient-reported measures, patient satisfaction was equally high between the groups. Similarly, Selber et al. found that free flaps in advanced age are well-tolerated without evidence of increasing complication rates and should be offered when indicated (17). Therefore, in the healthy elderly individual, neither method of reconstruction should be excluded and autologous tissue should be considered without prejudice.

When determining relevant risk factors in older populations, many studies have demonstrated that patient frailty may be more predictive of surgical complications than age (18). The Canada Study of Health and Aging (CSHA) developed a 70-item frailty index (CSHA-FI) that was based on this concept and assessed cognitive function, nutritional status, gait, grip strength, and comorbidities. The CHSA-FI has been shown to be strongly associated with adverse outcomes (19). The American College of Surgeons NSQIP database initially developed an 11 factor "modified frailty index" (mFI-11), and more recently, Subramaniam et al. have demonstrated a simplified 5 -factor modified frailty index (mFI-5) that is equally effective predictor of mortality and postoperative complications in all sub-specialties $(20,21)$. The factors comprising the $\mathrm{mFI}-5$ include functional status, diabetes, history of COPD, history of congestive heart failure, and hypertension requiring medication. Cuccolo et al. examined patient frailty versus age on outcomes following pedicled flap reconstruction, including for breast cancer. Although increased age was associated with increased risk of complications, the 5 -factor modified frailty index (mFI-5) held much stronger predictive capacity (22).

In summary, age should be considered a single factor in overall patient capacity for reconstruction, but should 
not be used to as a method of exclusion. Perioperative risk stratification, such as using the $\mathrm{mFI}-5$, is a better predictor of complications than age alone.

\section{Smokers}

For decades, smoking has been linked to cancer-related deaths and nicotine-induced vascular insufficiency. In the breast cancer patient, smoking is not only associated with higher risk of perioperative infection, but mastectomy flap necrosis, poor wound healing, and thrombosis.

In both alloplastic and autologous reconstruction, smoking has been found to increase the risk of developing post-operative complications (11,15,23-25). A study of independent risk factors for post-operative complications of autologous or implant-based reconstruction showed smoking was associated with the highest number of early overall complications. When smoking was combined with other potential risk factors such as obesity or preoperative radiation, the risk for complications rose exponentially (11). In a similar study looking at the effect of smoking on surgical complications with implant-based reconstruction alone, smoking was associated with an eightfold higher rate of complications than non-smokers (26). When examining the effects of smoking solely on autologous reconstructions, Chang et al. found that smokers were at significantly higher risk for mastectomy skin flap necrosis, abdominal flap necrosis, and hernia compared with non-smokers (23). Patients with a smoking history greater than 10 pack-years were noted to be at especially high-risk. Interestingly, no significant difference in complications was noted between former smokers and nonsmokers, when patients stopped smoking at least 4 weeks prior to surgery.

Although former smokers remain with an elevated lifetime risk of cancer, the reduced risk of perioperative complications has been replicated in multiple randomized controlled trials. A meta-analysis by Mills et al. pooled data from six randomized controlled trials regarding smoking cessation. Compared to controls, cessation programs were found to reduce overall risk of complications by $41 \%$, postoperative wound healing complications by $52 \%$, and surgical site infections by $60 \%$ (27). Furthermore, a significantly lower complication rate was observed in the trials which used a duration of smoking cessation 4 weeks or greater, with each week of smoking cessation progressively reducing postoperative risk out to six weeks.

The diagnosis of breast cancer can often induce anxiety and maladaptive coping mechanisms, including cigarette use. However, during initial consultation the oncologic treatment team may have a counseling opportunity at a time when concerned patients are most receptive to the idea of smoking cessation. In a meta-analysis regarding the effectiveness of smoking cessation interventions, the authors found that a smoker had approximately 1 in 8 chances of quitting without aid (28). However, this rate was doubled with the use of nicotine replacement therapy (NRT) and more than doubled when smoking cessation medications were used appropriately. Interestingly, in a randomized controlled trial, smoking cessation with NRT was shown to reduce postoperative complications as much as smoking cessation alone (29). Therefore, while absolute nicotine cessation for at least 4 weeks is the optimal recommendation for patients, NRT and adjunct medications may provide the highest chance of adherence to a cessation regimen with minimal wound healing complications (30).

\section{Obese}

For a multitude of socioeconomic reasons, many industrialized nations are facing an increasing obesity epidemic. If current trends continue, $30 \%$ of the United States population will be obese (BMI $\left.>30 \mathrm{~kg} / \mathrm{m}^{2}\right)$ by 2050 . Obesity contributes to chronic medical comorbidities such as hypertension, diabetes, and cardiovascular disease. In the breast reconstruction population, it is associated with increased risk of seroma, wound healing complications, infection, and reconstructive failure (15,26,31-41). In addition to perioperative morbidity, the aesthetics of breast reconstruction are challenged by large breast volume and truncal obesity.

Every reconstructive surgeon must decide their particular limit for different types of reconstruction in the obese patient. Importantly, different classes of obesity may do better than others. Hanwright et al. examined the differential effect of BMI on breast reconstruction in nearly 13,000 patients from multiple institutions (34). Overall, post-operative morbidity was significantly elevated in obese patients across all forms of reconstruction. In a large study by Fischer et al, the authors demonstrated that progressive obesity, defined by the World Health Organization Class I-III obesity guidelines, was associated with higher rates of overall perioperative morbidity, length of stay, operative time, and anesthesia risk (33). In particular, Class III obese patients experienced a $5.3 \%$ higher risk of return to the operating room and a $1.7 \%$ higher rate of flap or implant loss within 30 days. Through a meta-analysis, Panayi et al. 
found that obese women were 2.29 times more likely to experience surgical complications, 2.89 times more likely to have medical complications, and 1.91 times more likely to require reoperation in both prosthetic and autologous reconstruction (36).

In many practices, particularly within the United States, breast reconstructive surgeons are challenged by a patient population that is mostly obese, rather than by exception. If otherwise healthy, the surgeon must then determine the best method of reconstruction in this population. Several studies have evaluated obesity and type of reconstruction, with certain trends emerging.

Two recent publications evaluated patient-reported satisfaction and quality of life in obese patients undergoing autologous and implant-based reconstruction. The authors found that microsurgical breast reconstruction in obese patients yielded higher satisfaction with breasts, overall outcomes, psychosocial well-being, and chest physical wellbeing $(37,38)$. Similarly, Garvey et al. analyzed surgical complications in 700 obese patients who underwent alloplastic versus autologous reconstruction (42). Obese patients, especially class II and III, experienced higher failure rates with implant-based reconstruction than autologous reconstruction, especially if performed immediately. In another study examining BMI and prosthetic breast reconstruction, every unit increase in BMI was predictive of a $5.9 \%$ increase in the odds of a complication occurring, and a $7.9 \%$ increase in the odds of reconstructive failure (32). In regards to specific patientreported outcomes, limited implant volumes may also provide decreasing patient satisfaction trying to match increasing mastectomy volume. Therefore, when counseled appropriately relative to risk, patients may have greater long-term satisfaction with autologous reconstruction than with implants.

In obese patients who may otherwise not be candidates for tissue transfer, newer literature offers methods to improve outcomes with implant-based reconstruction. Prepectoral placement of tissue expanders with biologic mesh has proven to be safe and decrease pain and animation deformity, while increasing projection on the chest wall $(43,44)$. Indeed, retropectoral placement of tissue expanders may cause a concavity of the rib cage over time that is difficult to overcome with standard size implants in large women. A large study of outcomes after prepectoral implant reconstruction found that despite a tendency for class II and III obese patients to experience increased perioperative morbidity and reconstruction loss, on multivariate analysis the presence of diabetes and smoking were more predictive of any complication than obesity (45). These results suggest that while obesity should be considered, the global health of the patient and control of obesity-associated morbidities should be considered prior to exclusion from implant-based reconstruction.

Lastly, several studies have evaluated the role of oncoplastic reconstruction versus immediate prosthetic or autologous reconstruction. Tong et al. showed that oncoplastic patients were generally older, more obese, and had more comorbidities than their counterparts, yet they experienced fewer major complications requiring operative management, fewer complications delaying adjuvant treatment, and fewer incidences of hematoma/ seroma formation (46). Furthermore, oncoplastic breast reconstruction was an independent protective factor against major complications and complications that delayed adjuvant therapy. Therefore, in obese patients, especially those that are superobese or present with additional comorbidities, oncoplastic breast reconstruction may be the safest option.

\section{Ptosis}

The breast cancer patient with grade II or III ptosis is a difficult reconstructive dilemma. The excess skin envelope makes control of the breast pocket difficult, mastectomy skin flap perfusion questionable, and, in nipple-sparing mastectomies, symmetric position of the nipple-areolarcomplexes is extremely unpredictable. Traditionally, many patients with significant ptosis or macromastia are not offered nipple-sparing mastectomies or singlestage reconstructions. However, the improving survival of breast cancer patients, as well as the focus on post-cancer aesthetics and quality of life, no longer makes this limitation acceptable to patients (47). Several authors have described advances in control of the breast pocket and surgical techniques to increase the dependability of nipple-sparing mastectomies.

In 1990, Bostwick described his technique utilizing excess skin in the ptotic breast at the time of mastectomy as a deepithelialized inferiorly-based dermal flap and closure of the breast pocket in a Wise pattern (48). The Bostwick "Autoderm" technique has been described in multiple variations since, as a way to manage a redundant breast pocket while utilizing well-vascularized flaps over prostheses or expanders (49-54). Instead of disposing unnecessary lower pole tissue, the dermal flap becomes an essential part of the lateral and inferior pole borders and 
decreases the mechanical stress on mastectomy skin. Similar to the benefits of biologic mesh, the dermal pocket then defines the breast shape and allows the skin to be closed in a more aesthetic fashion (55). By maintaining the subdermal vascular plexus of the inferior flap, watershed areas that are often tenuous in a classic Wise pattern skin closure also have improved perfusion. The autoderm technique is now also used in prepectoral fashion when excessive laxity permits. This method has the added benefit of mitigating procedure costs, if used in lieu of acellular dermal matrix in appropriate cases.

Nipple-areolar preservation in the ptotic population is another domain receiving increased emphasis. To improve cosmesis in grade II and III ptosis, staged techniques for nipple-sparing mastectomy have been described by several authors (56-58). In 2012, Spear described a threestage approach to spare the NAC in which women first underwent an oncoplastic mastopexy/reduction, followed by a completion mastectomy through the mastopexy incisions, and then the final reconstruction with a prosthesis (59). This approach was demonstrated to be safe and effective with excellent aesthetic results. However, this technique was isolated to patients with small, peripheral tumors and negative nodal exams or patients undergoing prophylactic mastectomy. Patients with multicentric disease were excluded for oncologic safety. In response to this, Schwartz et al. developed an alternative staged technique suitable for both multicentric and isolated cancers, even in high-risk patients. Patients would first undergo NSM via a limited lateral incision, completion Wise pattern incision in the office 10 days later, operative repositioning of the skin and NAC two weeks later, and final prosthetic placement with acellular dermal matrix at 3 months (56). In both methods, the skin-reduction techniques are also useful in unilateral breast cancer reconstructions, because the same pattern can be applied to the contralateral side for symmetry $(50,51,60)$.

Mastopexy at the time of mastectomy has also been employed to improve autologous reconstruction results as well. Lin et al. investigated skin-sparing mastectomies with Wise pattern versus vertical mastopexy incision followed by immediate autologous reconstruction (61). Their results demonstrated acceptable results with both techniques, although there was a higher rate of mastectomy flap necrosis in the Wise pattern group. Rochlin et al. described a nipple-sparing technique using NAC delay procedure, followed by mastectomy via a lateral incision and Wise pattern in-folding of the dermis, and immediate autologous reconstruction (58).

Across all techniques, the surgeon capitalizes on the subdermal plexus to preserve vascularity to the mastectomy skin or nipple. This requires careful coordination with the surgical oncologist regarding incision placement and mastectomy flap thickness. Grade II or III ptosis is not a contraindication to any one type of breast reconstruction, but deserves a multidisciplinary approach to the timing of neoadjuvant, adjuvant, and surgical care.

\section{Summary}

(I) Elderly patients may be excellent candidates for breast reconstruction if otherwise healthy. Withholding autologous reconstruction is not recommended and may serve an older patient better by limiting the need for excessive revision operations;

(II) Smoking is contraindicated in all forms of breast reconstruction with prohibitively large complication rates. At least four weeks of abstinence is recommended, although the use of nicotine-replacement and associated medications may be permitted. Any patient that cannot comply should be offered delayed reconstruction;

(III) Obese patients present with multiple risks due to habitus and associated comorbidities, such as diabetes. Due to increased likelihood of prosthetic complications or failure, autologous and oncoplastic breast reconstruction are recommended;

(IV) Ptotic patients may be best managed by a staged approach, especially if they have grade III ptosis or desire a nipple-sparing mastectomy. Skin and nipple-areola perfusion are paramount and require a coordinated approach between breast and plastic surgeons.

\section{Conclusions}

When providing breast cancer treatment and reconstruction, all providers must consider the global health of the patient as well as the physical characteristics. High-risk patients should not be reflexively excluded from certain types of reconstruction, but counseled appropriately according to best evidence.

\section{Acknowledgments}

Funding: None. 


\section{Footnote}

Provenance and Peer Review: This article was commissioned by the Guest Editors (Charles E Butler, Carrie Chu, and Margaret Roubaud) for the series "New Frontiers in Breast Reconstruction" published in Gland Surgery. The article was sent for external peer review organized by the Guest Editors and the editorial office.

Conflicts of Interest: All authors have completed the ICMJE uniform disclosure form (available at http:// dx.doi.org/10.21037/gs-2020-nfbr-09). The series "New Frontiers in Breast Reconstruction" was commissioned by the editorial office without any funding or sponsorship. MSR served as the unpaid Guest Editor of the series. Dr. Patel serves as an unpaid editorial board member of Gland Surgery from Feb 2015 to Aug 2020. Dr. MSR reports other from Mentor Corporation, LLC, outside the submitted work. KM Patel reports other from Stryker Corporation, other from Elsevier, outside the submitted work. The other authors have no other conflicts of interest to declare.

Ethical Statement: The authors are accountable for all aspects of the work in ensuring that questions related to the accurancy or intergrity of any part of the work are appropriately investigated and resolved.

Open Access Statement: This is an Open Access article distributed in accordance with the Creative Commons Attribution-NonCommercial-NoDerivs 4.0 International License (CC BY-NC-ND 4.0), which permits the noncommercial replication and distribution of the article with the strict proviso that no changes or edits are made and the original work is properly cited (including links to both the formal publication through the relevant DOI and the license). See: https://creativecommons.org/licenses/by-nc-nd/4.0/.

\section{References}

1. Krueger EA, Wilkins EG, Stawderman M, et al. Complications and patient satisfaction following expander/implant breast reconstruction with and without radiotherapy. Int J Radiat Oncol Biol Phys 2001;49:713-21

2. Andrade WN, Baxter N, Semple JL. Clinical determinants of patient satisfaction with breast reconstruction. Plast Reconstr Surg 2001;107:46-54.

3. Gopie JP, Timman R, Hilhorst MT, et al. The shortterm psychological impact of complications after breast reconstruction. Psychooncology 2013;22:290-8.

4. Isern AE, Tengrup I, Loman N, et al. Aesthetic outcome, patient satisfaction, and health-related quality of life in women at high risk undergoing prophylactic mastectomy and immediate breast reconstruction. J Plast Reconstr Aesthet Surg 2008;61:1177-87.

5. Morrow M, Scott SK, Menck HR, et al. Factors influencing the use of breast reconstruction postmastectomy: a National Cancer Database study. J Am Coll Surg 2001;192:1.

6. Walton L, Ommen K, Audisio RA. Breast reconstruction in elderly women breast cancer: A review. Cancer Treatment Reviews 2011;37:353-57.

7. De Lorenzi F, Rietjens M, Soresina M, et al. Immediate breast reconstruction in the elderly: can it be considered an integral step of breast cancer treatment? The experience of the European Institute of Oncology, Milan. J Plast Reconstr Aesthet Surg 2010;63:511-5.

8. Bowman CC, Clugston PA, Courtemanche DJ, et al. Breast reconstruction in older women: should age be an exclusion criteria? Plast Reconstr Surg 2006;118:16-22.

9. Girotto JA, Nahabedian MY, Schreiber J. Breast reconstruction in the elderly: preserving an excellent quality of life. Ann Plast Surg 2003;50:572.

10. Oh DD, Flitcroft K, Brennan ME, et al. Patterns and outcomes of breast reconstruction in older womena systematic review of the literature. Eur J Surg Oncol 2016;42:604-15.

11. Thorarinsson A, Frojd V, Kolby L, et al. Patient determinants as independent risk factors for postoperative complications of breast reconstruction. Gland Surg 2017;6:355-67.

12. Lipa JE, Youssef AA, Kuerer HM, et al. Breast reconstruction in older women: advantages of autogenous tissue. Plast Reconstr Surg 2003;111:1110-21.

13. Laporta R, Sorotos M, Longo B, et al. Breast reconstruction in elderly patients: risk factors, clinical outcomes, and aesthetic results. J Reconstr Microsurg 2017;33:257-67.

14. Angarita FA, Dossa F, Hermann N, et al. Does timing of alloplastic breast reconstruction in older women impact immediate postoperative complications? An analysis of the American College of Surgeons National Surgical Quality Improvement Program (ACS NSQIP) database. Breast 2019;48:58-64.

15. McCarthy CM, Mehrara BJ, Riedel E, et al. Predicting complications following expander/implant breast reconstruction: an outcomes analysis based on preoperative 
risk. Plast Reconstr Surg 2008;121:1886-92.

16. Song D, Slater K, Papsdorf M, et al. Autologous reconstruction in women older than 65 years versus women younger than 65 years: a multicenter analysis. Ann Plast Surg 2016;76:155-63.

17. Selber JC, Bergey M, Sonnad SS, et al. Free flap breast reconstruction in advanced age: is it safe? Plast Reconstr Surg 2009;124:1015-22.

18. Searle SD, Mitnitski A, Gahbauer E, et al. A standard procedure from creating a frailty index. BMC Geriatr 2008;8:24.

19. Rockwood K, Howlett S, MacKnight C, et al. Prevalence, attributes, and outcomes of fitness and frailty in community-dwelling older adults: report from the Canadian study of health and aging. J Gerontol A Biol Sci Med Sci 2004;59:1310-17.

20. Velanovich V, Antoine H, Swartz A, et al. Accumulating deficits model of frailty and postoperative mortality and morbidity: its application to a national database. J Surg Res 2013;183:104-10.

21. Subramaniam S, Aalberg JJ, Soriano RP, et al. New 5-factor modified frailty-index using American College of Surgeons NSQIP data. J Am Coll Surg 2018;226:173-81.e8.

22. Cuccolo NG, Sparenberg S, Ibrahim MS, et al. Does age or frailty have more predictive effect on outcomes following pedicled flap reconstruction? An analysis of 44, 986 cases. J Plast Surg Hand Surg 2020;54:67-76.

23. Chang DW, Reece GP, Wang B, et al. Effect of smoking on complications in patients undergoing free TRAM flap breast reconstruction. Plast Reconstr Surg 2000;105:2374-80.

24. Christensen BO, Overgaard J, Kettner LO, et al. Longterm evaluation of postmastectomy breast reconstruction: Acta Oncol 2011;50:1053-61.

25. Hirsch EM, Seth AK, Kim JY, et al. Analysis of risk factors for complications in expander/implant breast reconstruction by stage of reconstruction. Plast Reconstr Surg 2014;134:692e-9e.

26. Sadok N, Krabbe-Timmerman IS, de Bock GH, et al. The effect of smoking and body mass index on the complication rate of alloplastic breast reconstruction. Scand J Surg 2020;109:143-50.

27. Mills E, Eyawo O, Lockhart I, et al. Smoking cessation reduces postoperative complications: A systematic review and meta-analysis. Am J med 2011;124:144-54.e8.

28. Mahvan T, Namdar R, Voorhees K, et al. Clinical inquiry: which cessation interventions work best? J Fam Pract 2011;60:430-1.
29. Sorensen LT, Karlsmark T, Gottrup F. Abstinence from smoking reduces incisional wound infection: a randomized controlled trial. Ann Surg 2003;238:1-5.

30. Rinker B. The evils of nicotine: an evidence-based guide to smoking and plastic surgery. Ann Plast Surg 2013;70:599-605.

31. Chen CL, Shore AD, Johns R, et al. The impact of obesity on breast surgery complications. Plast Reconstr Surg 2011;128:395e-402e.

32. Nguyen KT, Hanwright PJ, Smetona JT, et al. Body mass index as a continuous predictor of outcomes after expander-implant breast reconstruction. Ann Plast Surg 2014;73:19-24.

33. Fischer JP, Nelson JP, Kovach SJ, et al. Impact of obesity on outcomes in breast reconstruction: analysis of 15, 937 patients from the ACS-NSQIP datasets. J Am Coll Surg 2013;217:656-64.

34. Hanwright PJ, Davila AA, Hirsch EM, et al. The differential effect of BMI on prosthetic versus autogenous breast reconstruction: a multivariate analysis of 12,986 patients. Breast 2013;22:938-45.

35. Yuen JC, Coleman CA, Erickson SW. Obesity-related risk factors in implant-based breast reconstruction using Alloderm. Plast Reconstr Surg Glob Open 2017;5:e1231.

36. Panayi AC, Agha RA, Sieber BA, et al. Impact of obesity on outcomes in breast reconstruction: a systematic review and metaanalysis. J Reconstr Microsurg 2018;34:363-75.

37. Kamel GN, Mehta K, Nash D, et al. Patient-reported satisfaction and quality of life in obese patients: a comparison between microsurgical and prosthetic implant recipients. Plast Reconstr Surg 2019;144:960e-6e.

38. Klement KA, Hijjawi JB, LoGiudice JA, et al. Microsurgical breast reconstruction in the obese: a better option than tissue expander/implant reconstruction? Plast Reconstr Surg 2019;144:539-46.

39. Berry T, Brooks S, Sydow N, et al. Complication rates of radiation on tissue expander and autologous tissue breast reconstruction. Ann Surg Oncol 2010;17:202-10.

40. Roy M, Sebastiampillai S, Haykal S, et al. Development and validation of a risk stratification model for immediate microvascular breast reconstruction. J Surg Oncol 2019;120:1177-83.

41. Alderman A, Gutowski K, Ahuja A, et al. ASPS Clinical Practice Guideline Summary on Breast Reconstruction with Expanders and Implants. Plast Reconstr Surg 2014;134:648e-55e.

42. Garvey PB, Villa MT, Rozanski AT, et al. The advantages of free abdominal-based flaps over implants for breast 
reconstruction in obese patients. Plast Reconstr Surg 2012;130:991-1000.

43. Sbitany H, Piper M, Lentz R, et al. Prepectoral breast reconstruction: a safe alternative to submuscular prosthetic reconstruction following nipple-sparing mastectomy. Plast Reconstr Surg 2017;140:432-43.

44. Elswick SM, Harless CA, Bishop SA. Prepectoral implantbased breast reconstruction with postmastectomy radiation therapy. Plast Reconstr Surg 2018;142:1-12.

45. Gabriel A, Sigalove S, Sigalove NM, et al. Effect of body mass index on outcomes after prepectoral breast reconstruction. Plast Reconstr Surg 2019;144:550-8.

46. Tong WM, Baumann DP, Villa MT, et al. Obese women experience fewer complications after oncoplastic breast repair following partial mastectomy than after immediate total breast reconstruction. Plast Reconstr Surg 2016;137:777-91.

47. Wellisch DK, Schain WS, Noone RB, et al. The psychological contribution of nipple addition in breast reconstruction. Plast Reconstr Surg 1987;80:699-704.

48. Bostwick J. Prophylactic (risk-reducing) mastectomy and reconstruction. In: Plastic and Reconstructive Breast Surgery. Vol II. St Louis: Quality Medical Publishing, 1990;1369-73.

49. Ladizinsky DA, Sandholm PH, Jewett ST, et al. Breast reconstruction with the Bostwick autoderm technique. Plast Reconstr Surg 2013;132:261-70.

50. Carlson GW, Bostwick J 3rd, Styblo TM, et al. Skinsparing mastectomy. Oncologic and reconstructive considerations. Ann Surg 1997;225:570-5; discussion 575-8.

51. Hammond DC, Capraro PA, Ozolins EB, et al. Use of a skin-sparing reduction pattern to create a combination skin-muscle flap pocket in immediate breast reconstruction. Plast Reconstr Surg 2002;110:206-11.

52. Losken A, Collins BA, Carlson GW. Dual-plane prosthetic reconstruction using the modified Wise pattern mastectomy and fasciocutaneous flap in women with macromastia. Plast Reconstr Surg 2010;126:731-8.

53. Nava MB, Cortinovis U, Ottolenghi J, et al. Skin-reducing mastectomy. Plast Reconstr Surg 2006;118:603-10; discussion 611-3.

54. Friedman HI, Talebagha S, Gilstrap J, et al. Wise Pattern Direct Implant Breast Reconstruction: A Review and Improved Outcomes Using Dermal Matrix. Plast Reconstr Surg Glob Open 2019;7:e2439.

55. Hon HH, Mubang RN, Wernick BD, et al. Acellular dermal matrix versus inferior deepithelialized flap breast reconstruction: equivalent outcomes, with increased cost. Plast Reconstr Surg Glob Open 2017;5:e1382.

56. Schwartz JC. A new approach to nipple-sparing mastectomy and reconstruction in the high risk ptotic patient. Plast Reconstr Surg Glob Open 2018;6:e1779.

57. Munhoz AM, Montag E, Filassi JR, et al. Immediate nipple-areola-sparing mastectomy reconstruction: an update on oncological and reconstruction techniques. World J Clin Oncol 2014;5:478-94.

58. Rochlin DH, Nguyen DH. Deepithelialized skin reduction preserves skin and nipple perfusion in immediate reconstruction of large and ptotic breasts. Ann Plast Surg 2018;81:22-7.

59. Spear SL, Rottman SJ, Seiboth LA, et al. Breast reconstruction using a staged nipple-sparing mastectomy following mastopexy or reduction. Plast Reconstr Surg 2012;129:572-81.

60. Hunter JE and Malata CM. Refinements of the LeJour vertical mammoplasty skin pattern for skin-sparing mastectomy and immediate breast reconstruction. J Plast Reconstr Aesthet Surg 2007;60:471-81.

61. Lin IC, Bergey M, Sonnad SS, et al. Management of the ptotic or hypertrophic breast in immediate autologous breast reconstruction: a comparison between the Wise and vertical reduction patterns for mastectomy. Ann Plast Surg 2013;70:264-70.
Cite this article as: Roubaud MS, Carey JN, Vartanian E, Patel KM. Breast reconstruction in the high-risk population: current review of the literature and practice guidelines. Gland Surg 2021;10(1):479-486. doi: 10.21037/gs-2020-nfbr-09 